\title{
Scleractinian corals incorporate microplastic particles: identification from a laboratory study
}

\author{
Florian Hierl ${ }^{1,2}$ (D) Henry C. Wu ${ }^{1}$ (D) $\cdot$ Hildegard Westphal ${ }^{1,2}$ (B) \\ Received: 25 November 2020 / Accepted: 26 February 2021 / Published online: 15 March 2021 \\ (C) The Author(s) 2021
}

\begin{abstract}
Microplastics have been detected on beaches and in the ocean from surface habitats to the deep-sea. Microplastics can be mistaken for food items by marine organisms, posing a potential risk for bioaccumulation and biomagnification in the food chain. Our understanding of microplastic pollution effects on ecosystem and physiological processes of coral reefs is still limited. This study contributes to the understanding of effects of microplastic pollution on skeletal precipitation of hermatypic corals. In a five month aquarium-based experiment, specimens of four tropical species were temporarily exposed to high concentrations (ca. $\left.0.5 \mathrm{~g} \mathrm{~L}^{-1}\right)$ of polyethylene terephthalate (PET) microplastic particles $(<500 \mu \mathrm{m})$. The coral specimens all survived this treatment and show skeletal growth. The skeletal material produced during the experiment, however, incorporated plastic particles and plastic fibres in the aragonitic structure. Long-term consequences of such inclusions on skeletal properties such as stability are yet unknown.
\end{abstract}

Keywords Incorporation $\cdot$ Encrustation $\cdot$ Spectroscopy $\cdot$ Microplastic $\cdot$ Calcification $\cdot$ Coral skeleton

\section{Introduction}

In the past five decades, marine environments have been exposed to increasing amounts of plastic pollution, recently gaining considerable attention in the scientific community (Stefatos et al. 1999; GESAMP 2015). Pollution by plastic litter in the oceans was first reported in the early 1970s (Carpenter and Smith 1972; Carpenter et al. 1972; Fowler 1987), but only recognized later as an urgent topic (Stefatos et al. 1999; Andrady 2011). The amount of synthetic plastic pieces entering the marine ecosystem is alarming, and has been estimated to sum up to some 12.7 million tons per year (Jambeck et al. 2015).

All marine environments are thought to be subject to plastic pollution, ranging from shallow surface waters to deep-sea habitats (Fischer et al. 2015). The widespread dispersion of

Responsible Editor: Philippe Garrigues

Florian Hierl

florian.hierl@leibniz-zmt.de

1 Leibniz Centre for Tropical Marine Research (ZMT), Fahrenheitstraße 6, 28359 Bremen, Germany

2 Faculty of Geosciences, University of Bremen, Klagenfurter Straße 4, 28359 Bremen, Germany many types of plastics across all marine ecosystems derives from their buoyancy in seawater (Derraik 2002; Reisser et al. 2015). The highest plastic concentrations of floating pieces can be found accumulated in the oceanic gyres (Berloff et al. 2002; Maximenko et al. 2012; Eriksen et al. 2014).

Recent studies show that besides the large amounts of macroplastics floating on the sea surface, an unknown portion of microplastic particles (generally defined by a size $<5 \mathrm{~mm}$ ) pollutes the marine realm (Moore 2008; Andrady 2011; Wright et al. 2013; Eriksen et al. 2013; GESAMP 2015). These particles occur in a wide variety of shapes and sizes throughout the water column and are being deposited in sediments around the globe (Fischer et al. 2015; Van Cauwenberghe et al. 2015; Kane et al. 2020).

Marine plastic litter mostly derives from package materials from land-based sources (Pruter 1987; Gregory 1991; Derraik 2002). Polyethylene (PE), polyethylene terephthalate (PET), polystyrene (PS), polypropylene (PP), and polyvinyl chloride (PVC) are the most common types of plastic in the marine environment (Andrady 2011). Two types of marine microplastics can be distinguished (Cole et al. 2011). Particles that already have the shape and size of microplastics when entering the marine environment are called primary microplastics and are produced for cosmetics, hand and facial cleaners, or are by-products of air-blasting and sewage plants (Fendall and Sewell 2009; 
Browne et al. 2010; Cole et al. 2011). Secondary microplastics are derived from the processes of degradation of larger plastic pieces and make up the larger portion of the two (Barnes et al. 2009; Wang et al. 2016). Decomposition and therefore the creation of secondary microplastics are driven by thermal-oxidative, photolytic, abrasive, and biotic processes (Andrady 2011; Gewert et al. 2015; Weinstein et al. 2016).

Due to their size and the usage of toxic components during plastic production, microplastics are considered to be a threat to marine organisms, including scleractinian corals (Hall et al. 2015; Hahladakis et al. 2018; Reichert et al. 2018, 2019; Hankins et al. 2018). Increasing numbers of studies report potential risks of microplastic pollution on coral health. The results are based on laboratory studies (Hall et al. 2015; Allen et al. 2017; Reichert et al. 2018, 2019; Martin et al. 2019) and environmental assessments (Connors 2017; Rotjan et al. 2019; Ding et al. 2019; Tan et al. 2020).

Laboratory studies have demonstrated that corals ingest and egest microplastic particles (Hall et al. 2015; Allen et al. 2017; Reichert et al. 2018; Hankins et al. 2018). Elevated concentrations of ingested microplastics in the mesenterial gut cavity tissue are expected to be a risk for coral health (Hall et al. 2015) because plastic fragments are not broken down in the gut (Allen et al. 2017), potentially resulting in gut blockage (Stamper et al. 2006), false satiation and reduced energy resources (Wright et al. 2013; Watts et al. 2015). Corals have been shown to ingest microplastic particles almost ten times more frequently than sediment particles of comparable size, the preference for plastics been caused by phagostimulants contained in plastic (Allen et al. 2017).

Additionally, direct contact with microplastic particles can cause tissue necrosis, overgrowth, and even migration into the skeleton-tissue interface (Reichert et al. 2018; Ding et al. 2019). The effects of microplastic particles on coral health and coral growth rate appear to be species-specific and also depend on the duration of exposure to microplastics (Hankins et al. 2018; Reichert et al. 2019).

Another dimension of microplastic impact on coral health emerges from contaminated microplastic particles e.g. with polycyclic aromatic hydrocarbons (PAHs), persistent organic pollutants (POPs), heavy metals or pathogens resulting in increased spreading of diseases amongst coral colonies (Rios et al. 2007; Teuten et al. 2007, 2009; Ashton et al. 2010; Bakir et al. 2012; Fisner et al. 2013; Kirstein et al. 2016; Lamb et al. 2018; Hahladakis et al. 2018; Rotjan et al. 2019). Several studies tested the adhesion potential, as well as the plastic properties that lead to ingestion and egestion, the amount ingested over a given time, and the physiological effects of microplastics on growth rates in scleractinian corals (Hall et al. 2015; Allen et al. 2017; Reichert et al. 2018, 2019; Hankins et al. 2018; Martin et al. 2019; Corona et al. 2020). The processes following ingestion and overgrowth, however, are still poorly understood.
The present study investigates the impacts of microplastics on the precipitation of skeletal material of reef-building scleractinian corals to gain knowledge on long-term exposure risks in polluted waters. Special focus is on encrustations of plastic particles and fibres in coral skeletal material. The mesocosm tank experiment reported here extended over a time interval of five months and involved four different scleractinian coral species. Four coral species were chosen, namely, Acropora valida [Dana, 1846], Montipora capricornis [Veron, 1985], Pocillopora damicornis [Linnaeus, 1758] and Seriatopora hystrix [Dana, 1846] that represent different morphologies. The aim was to test whether the shape of the coral influences the encrustation potential of microplastic in the skeleton, analogous to the influence of morphology on the effect of carbonate and siliciclastic sediment grains, where a branching morphology is favourable in terms of sediment rejection compared to a plate-like morphology (Duckworth et al. 2017).

\section{Material and methods}

\section{Aquaria setup}

Specimens of the four coral species (A. valida, M. capricornis, $P$. damicornis and $S$. hystrix) were exposed to microplastic particles for 24 hours every two weeks over five months in a fully controlled lab experiment. These four hermatypic species were chosen because of their structural and morphological differences and differences in polyp sizes. S. hystrix, $P$. damicornis and A. valida are branching corals, while $M$. capricornis has a plate-like growth. $P$. damicornis has the largest polyp cavity compared to the other species. In $S$. hystrix the polyps are positioned much closer to each other compared to $P$. damicornis and A. valida.

Before the experiment, coral clones were produced by taking coral fragments of 4-10 cm length from a parent colony cultured at the Leibniz Centre for Tropical Marine Research (ZMT) aquaria facility in Bremen, Germany. These were glued onto ceramic stubs using a one-component glue (Coral Glue, EcoTech Marine, Allentown, PA, USA) and placed in mesocosm tanks at this aquarium facility which utilizes a fully recirculating system with artificial seawater using Red Sea salts. The microbiome in the tanks was allowed to stabilise for an 8-week phase before the corals were introduced in. The coral fragments were then acclimatised for six weeks prior to the start of the experiment.

The experimental design included four hosting tanks and four separate exposure tanks. Corals were held in the hosting tanks during breaks between exposure cycles. Of the four exposure tanks, two were equipped with a constant circulation of microplastics, while two tanks for control treatment did not contain microplastics (Fig. 1). Each of the four hosting tanks 


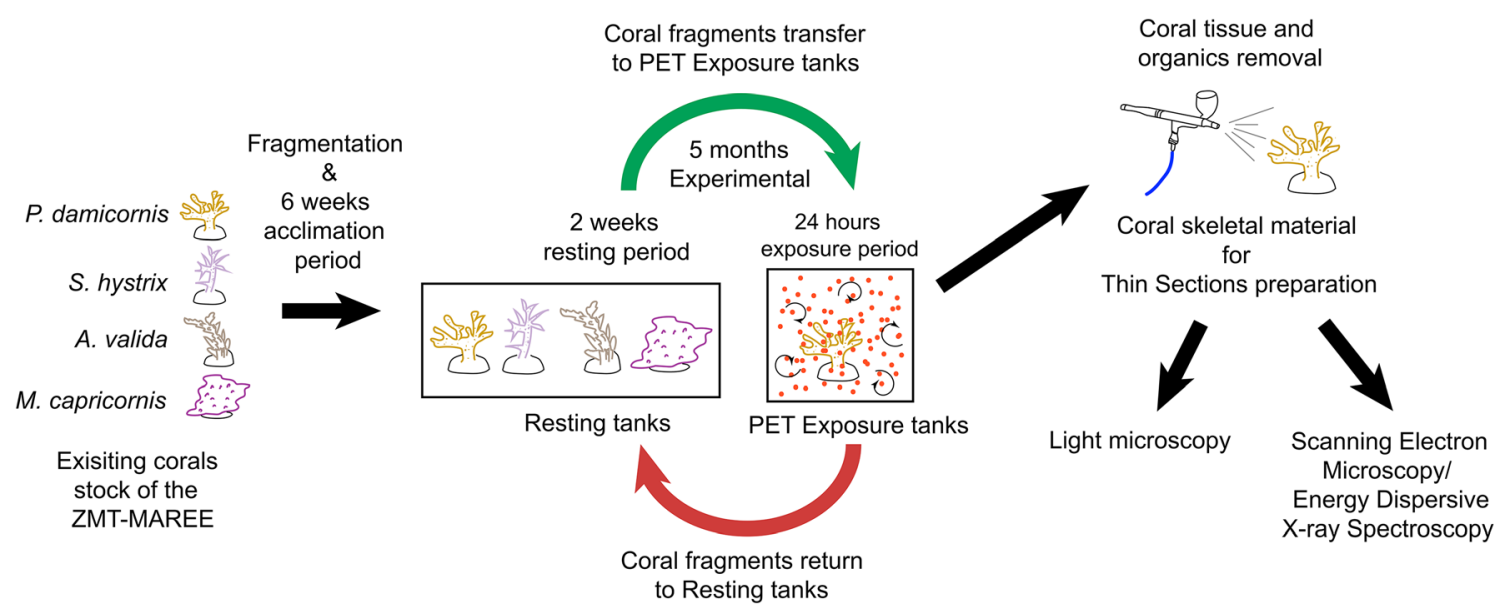

Fig. 1 Schematic diagram of the experimental setup and exposure cycles. The diagram shows the fragmentation, the transfer of fragments between microplastic exposure and resting tanks and the post-experimental processing steps

held 16 coral fragments (i.e. four per species), summing up to 64 fragments for the experiment. Corals were fed with live Artemia (10 ml Artemia-water-mixture) twice a week. The Artemia-water-mixture was also added to the treatment tank during the 24 hour exposure to stimulate food-intake.

\section{Microplastic treatment}

For exposure, corals were relocated from the four hosting tanks to the exposure tanks for 24 hours every two weeks (Fig. 1). The two treatment tanks without microplastic served as a procedural control for stress introduced by the movement from hosting tank to treatment tank.

Microplastic particles used in the experiment consist of pristine PET purchased from Goodfellow Cambridge Limited. PET was chosen because of its wide abundance in ocean waters, its high density $\left(1.38 \mathrm{~g} \mathrm{~cm}^{-3}\right)$ that allows it to settle on the coral surfaces, and as it is not toxic, thus reducing the stress parameters that affect the coral. The particles have an irregular shape and their size distribution ranges from $\sim 5$ to $\sim 500 \mu \mathrm{m}$. The concentration of microplastic particles in the exposure setup was maintained at $0.5 \mathrm{~g} \mathrm{~L}^{-1}$ seawater. The microplastic particles were kept moving in the water column using a circulating streaming pump setup. Circulation decreased over time as an effect of the formation of biofilms on the particles causing increased particle weight with time. This biofilm formation, as well as a minimal loss of plastic material due to ingestion and adhesion, necessitated an exchange of microplastic particles in the exposure setup every two to three exposures.

\section{Seawater chemistry and maintenance of hosting tanks}

Water chemistry conditions in the tanks were regularly monitored and kept stable during the duration of the experiment with a $10 \%$ water exchange weekly. Nitrate, phosphate and alkalinity were measured using microtiter plate readers (TECAN, Infinite 200 PRO F, Switzerland). Magnesium and calcium concentrations were determined using Inductively Coupled Plasma-Optical Emission Spectrometry (ICP-OES) following standard protocols for seawater analysis; some measurements were completed by hand using a NYOS titration kit for the coral reef aquaria.

Mean tank water temperature was kept at $24.97 \pm 0.77^{\circ} \mathrm{C}$ with a practical salinity of $34.8 \pm 0.38$. In a natural setting, phosphate and nitrate are introduced in the corals' living environment by organic matter produced by reef fish. This aquaria setup lacked the introduction of organic matter as a result of the experimental design, thus requiring supplements provided artificially to enhance the stability of the system. Therefore, for the last six weeks of the experiment, the nutrition components Sangokai Nutri complex providing additional phosphate and Sangokai Nutri complete providing both nitrate and phosphate were added directly into the water column of the resting tanks. Both additives were supplied in a concentration of $1 \mathrm{ml}$ per $100 \mathrm{~L}$ twice a week. Nitrate and phosphate levels were kept below detection level $\left(\mathrm{NO}_{3}{ }^{-}: 0.08\right.$ $\left.\mu \mathrm{M} ; \mathrm{PO}_{4}{ }^{3-}: 0.07 \mu \mathrm{M}\right)$. The water chemistry parameters directly influencing calcification were kept stable throughout the experiment $\left(\mathrm{Mg}^{2+}\right.$ : $1300 \mathrm{mg} \mathrm{L}^{-1}, \mathrm{Ca}^{2+}: 410 \mathrm{mg} \mathrm{L}^{-1}$, Alkalinity: $\left.8^{\circ} \mathrm{dH}=1.429 \mathrm{mmol} / \mathrm{l}\right)$. During exposure, the seawater temperature was maintained at $25^{\circ} \mathrm{C}$ using a Shego thermostat and a titanium tube heating element. Salinity and $\mathrm{pH}$ levels of the exposure setup were monitored before and after the exposure to ensure consistent conditions. Additional information regarding the seawater chemistry and physical parameters are given in the Supplementary Materials (Table S1-3).

Lighting for the hosting and the exposure tanks was implemented by Aqua Illumination Hydra fifty-two HD LED lamps with a sunlight and moonlight simulation program $(11: 13 \mathrm{~h}$ 
day/night ratio) with synchronised light spectra and intensities across all tanks. Light levels were aligned to the tanks of coral parent colonies peaking every day with an intensity of around $200 \mu \mathrm{mol} \mathrm{s}{ }^{-1} \mathrm{~m}^{-2}$.

Each tank held several snails of the genus Trochus and also one shrimp (Lysmata amboiensis) to ensure a clean and healthy state of the aquaria. The Lysmata amboiensis were fed twice a day with freeze-dried food.

\section{Sample preparation}

At the end of the five month experiment, the coral fragments were taken from the tanks and processed for further analysis. The corals from the control runs were collected first to avoid cross-contamination with the samples exposed to the microplastics. Within those groups, the specimens of the four species were processed in separate batches to avoid contamination across those species. Organic material was removed from the corals with a high-pressure painting sprayer pistol filled with 18.2 M $\Omega$ milli-Q water. The vertical growth of the corals (linear extension) was determined by comparing images taken before and after the experimental phase. The results were compared to species-specific growth rates based on vertical linear extension of $S$. hystrix, $P$. damicornis and A. valida calculated from the Coral Trait Database (Version 1.1.1) (Madin et al. 2016), while no such information was available for M. capricornis. Thin sections of the coral skeletal samples were prepared from the outermost $3-5 \mathrm{~cm}$ of the branching tips. The thin sections were stained for $30 \mathrm{~s}$ in a $0.2 \% \mathrm{HCl}$ and $0.2 \mathrm{~g} / 100 \mathrm{ml}$ Alizarin red $\mathrm{S}$ solution (Warne 1962) to differentiate coral skeletal aragonite (stained red) from microplastic particles (not stained). The thin sections were sputter coated with gold for scanning electron microscopy (SEM) and energy dispersive $\mathrm{X}$-ray spectroscopy (EDX) analyses. In order to validate our observational method, calibration thin sections of pristine plastic particles (PET) and pieces of coral skeleton were prepared (Fig. 4a).

\section{Microscopical examination of the skeletons}

For light microscopy, a Keyence VHX 5000 was used to capture high-resolution images of the thin sections. For confirming the identification of skeletal materials, microplastic particles and embedding epoxy resin, EDX analytical technique was performed using the Tescan Vega XMU Scanning Electron Microscope. Brightness and contrast were post-processed in some images with Affinity Photo (Version 1.7.2) to reach optimal comparability across multiple thin sections. ImageJ image processing program was used for size measurements of microplastic particles (Version 1.52q) (Schneider et al. 2012).

\section{Results}

\section{Visual observations during experimentation}

All corals survived the experiment in both, exposure or control treatments. Colour intensities of all corals faded equally for control and exposure, but no bleaching was observed. During the microplastic exposures, the corals were observed to ingest and egest particles (Fig. 2). Growth of a few centimetres was observed across species in images taken before and after experiment (Fig. 3a and b). Corals displayed increased mucus production compared to control corals during the first hours of exposure to microplastic particles (Fig. 3c and d). Inter-species differences in the amount of mucus expelled were observed with the highest amounts produced by S. hystrix (Fig. 3d). The lowest amounts of mucus were expelled by $M$. capricornis, while mucus production of $P$. damicornis and A. valida was slightly higher and comparable between the two species.

\section{Thin section analyses}

Thin sections of 32 coral fragments were inspected of which 13 are from the control runs and 19 from microplastic

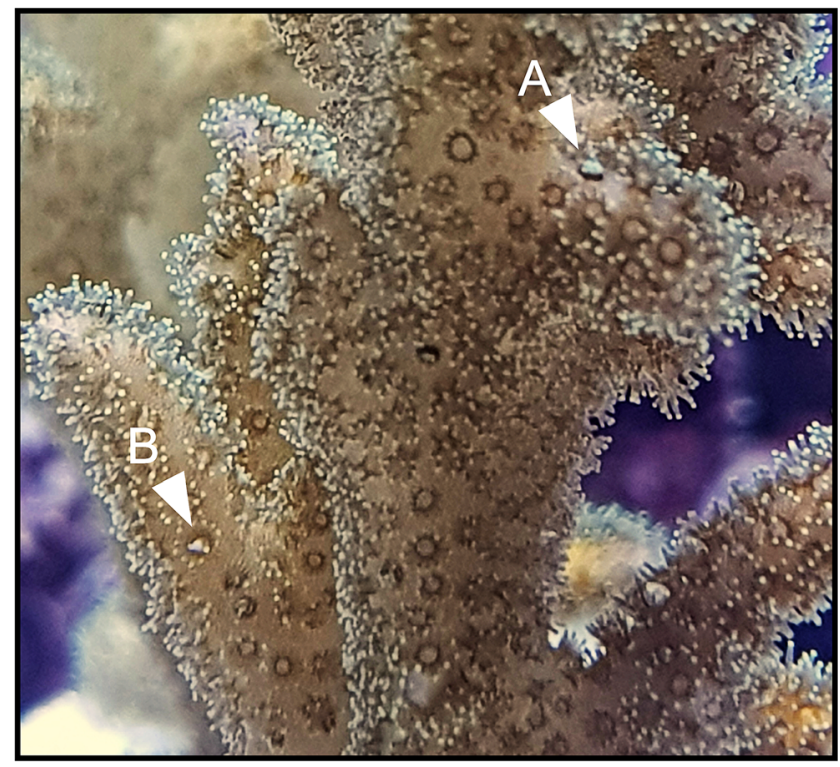

Fig. 2 Ingestion and egestion of microplastic particles observed during and after microplastic exposure. White arrows indicate polyps that ingested microplastics. Polyp is closed after ingestion of microplastics (A). Polyp is opened; microplastic particle is observed inside the polyp mouth (B) 
Fig. 3 Visual observations during experimentation. a Coral control tank during the first round of exposure. b Coral control tank during the last round of exposure. A direct comparison of $\mathbf{a}$ and $\mathbf{b}$ visualizes extent of coral growth over the five month duration of the experiment. c Exposure tank during microplastic exposure. Notable increase in mucus production is visible when compared to $\mathbf{a}$ and $\mathbf{b}$. d Extreme mucus production (white arrow) of $S$. hystrix inside the experimental setup during the first hours of exposure to microplastic

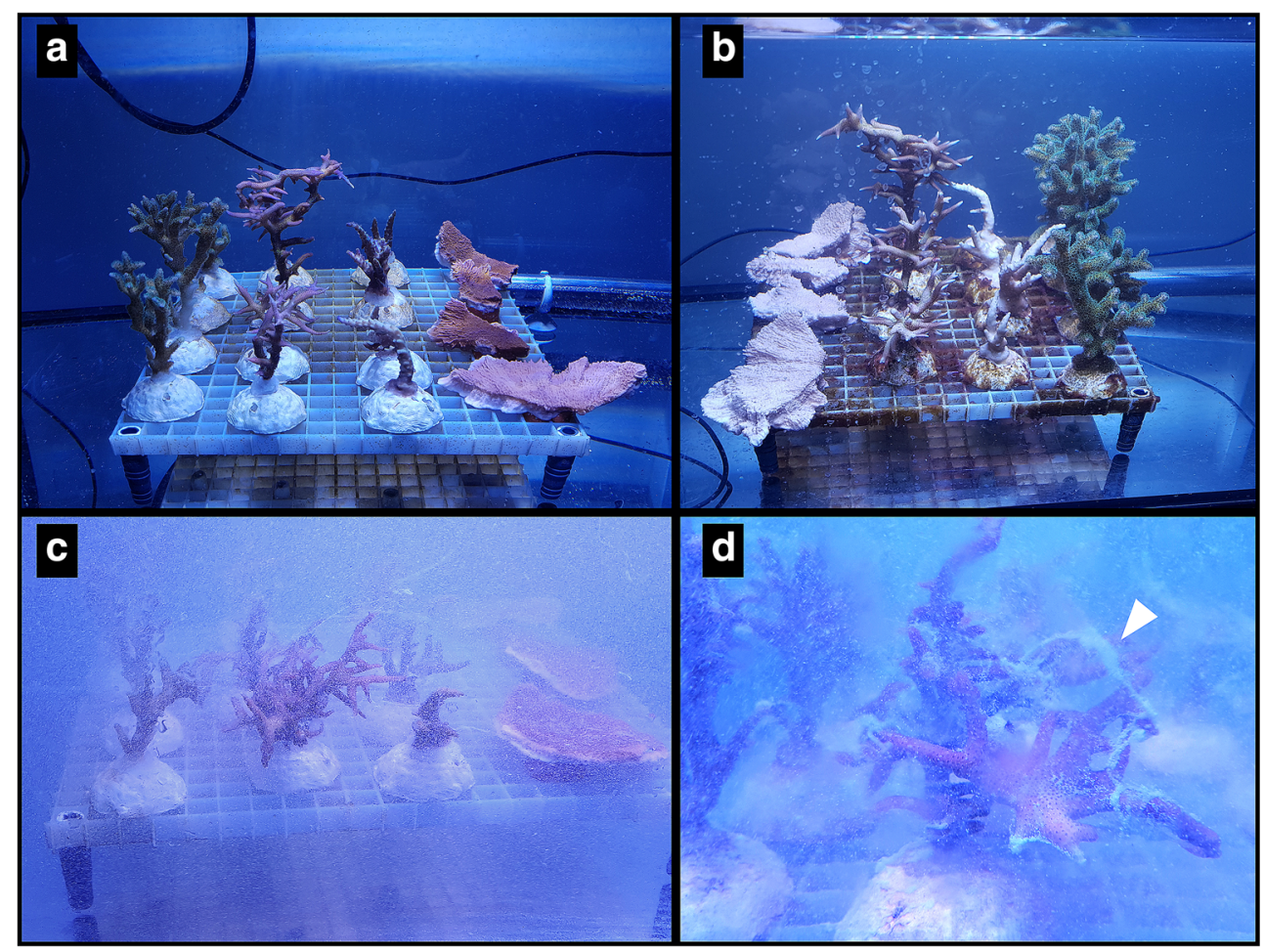

exposure treatments. In seven specimens of the exposure group, 10 particles interpreted as microplastic have been found to be associated (no visible encrustation) and incorporated (visible encrustation) in the skeletons of $S$. hystrix $(n=4)$ and M. capricornis $(n=3)$ (Fig. 4b-d). In contrast, no particles were identified in the specimens of A. valida and $P$. damicornis in the exposure treatment. Also, the control run specimens did not show any particles.

While there were clear visible structures in the coral skeleton (e.g. elongated crystals and centres of calcification), the microplastic particles exhibited a more random and homogenic crystallographic structure when inspected under a polarized light microscope (Fig. 4b-f). The microplastic particles identified in the thin sections of $S$. hystrix (Fig. 4bd) and M. capricornis (Fig. 4e and f) are present mostly in the outermost polyp layer in close proximity to where the polypcorallite interface would be. In S. hystrix (Fig. 4b-d), the particles were located on and in the outermost tips of the branches. In two $S$. hystrix sections (Fig. 4b), the integration of particles into the coral skeleton was obvious by a thin layer of carbonate having overgrown the particles (Fig. 4b), the other two $S$. hystrix thin sections did not display incorporation. Particles in M. capricornis (Fig. 4e and f) were present on top and inside the outer layer of the coral skeleton, sitting between the skeletal walls and septa, but with no visible encrustation happening. Those particles found in microplastic exposure thin sections of $S$. hystrix and M. capricornis had a mean length of $117 \mu \mathrm{m}$ and a mean width of $82 \mu \mathrm{m}$.

\section{SEM/EDX analysis}

Backscattered electron microscopy (BSE) showed a clear difference between coral skeleton and the two types of polymers (PET and epoxy resin) while between the latter, only a subtle difference is present. In descending order, coral skeleton, microplastic particles, and epoxy resin differed from light grey to dark grey. Resulting from the curing process of the epoxy resin, a characteristic gap between resin and the other two materials was evident (Fig. 5a, grey arrow). The surface structure of the coral skeleton displayed visible areas with aragonite crystals (Fig. 5a, black arrow). A differentiation between epoxy and microplastic by their surface structure was not possible. Furrows in both polymer structures were results of the thin section preparation process originating from the low hardness of the polymer materials (Fig. 5a, white arrow). Furrows can also be seen in carbonate material, but with much less reprint.

EDX elemental analyses were performed on all seven thin sections from the PET-exposure treatment that contained plastic particles. Measurements were dominated by three different elemental spectra types similar to M1, M2 and M3 in the calibration thin section (Fig. 5a). The elemental spectra in this example (Fig. 5b) were labelled as M4 to M7. M4 and M5 are characterised by a high peak in calcium $(\mathrm{Ca})$ and a smaller peak in magnesium $(\mathrm{Mg})$ and oxygen $(\mathrm{O})$ (Fig. 5b, panel M4 and M5). M6 is characterised by a high peak in oxygen $(\mathrm{O})$ (Fig. 5b, panel M6). M7 is characterised by a small peak in 
Fig. 4 Microplastic particle and coral skeleton thin section comparison. Thin sections of a pristine plastic and coral skeleton particles as standards, and $\mathbf{b}$ of $S$. hystrix and M. capricornis fragments after exposure to microplastic particles. Aragonitic corals (C) were stained (red), while the stain did not affect plastic particles $(\mathrm{P})$ that appear yellow-brown. Cc indicates the centre of calcification of corals. c Two unstained plastic particles located on the outer edge of $S$. hystrix skeleton, fine connections to the skeleton can be identified with polarized light microscopy. d Microplastic particle in the corallite cavity of $S$. hystrix. e Microplastic particle located close to the outer layer of M. capricornis skeleton. $\mathbf{f}$ Microplastic particle without direct visible connection to the skeleton found in a M. capricornis thin section
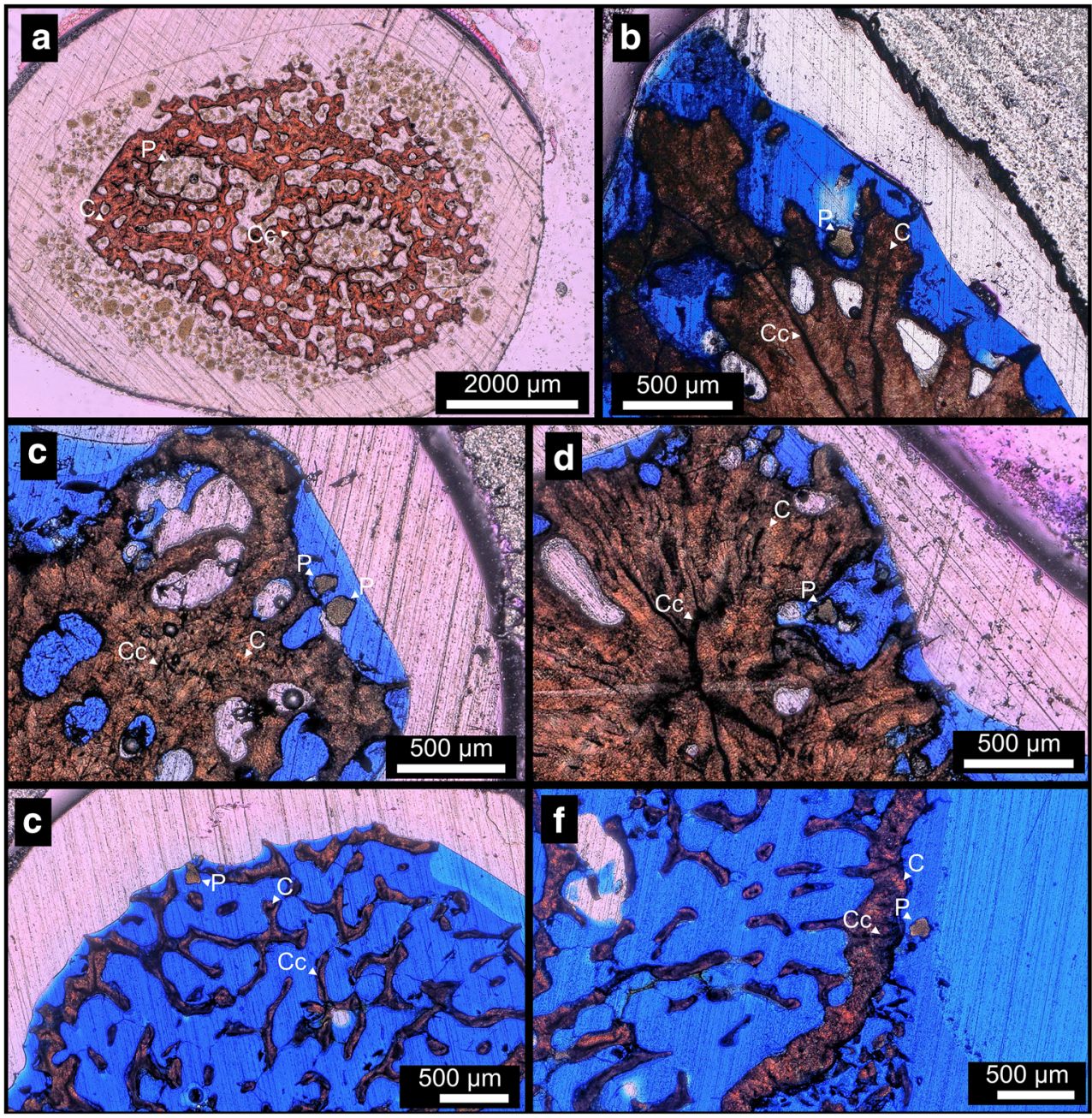

oxygen $(\mathrm{O})$ and the presence of chlorine $(\mathrm{Cl})$ (Fig. 5b, panel M7). All particles previously identified by light microscopy are confirmed as microplastics based on the calibration with the artificially produced thin section. The BSE analysis of an encrusted particle (Fig. 5b, white arrow) shows that the microplastic particle is surrounded almost entirely by a $2-15$ $\mu \mathrm{m}$ thick layer of carbonate material and set in the lower part of the corallite. In the other thin sections, particles were either situated in the corallite cavity of the outer branches, or on random locations attached to the outer skeletal portion.

\section{EDX analyses}

The EDX detector was used to identify the characteristic elemental composition of the materials in the calibration thin section of microplastic particles next to coral skeletal aragonite embedded in epoxy resin (Fig. 5a). These three components could be clearly distinguished in EDX, the coral skeletal materials being characterised by calcium $(\mathrm{Ca})$, magnesium $(\mathrm{Mg}$ ), and oxygen $(\mathrm{O})$ peaks (Fig. 5a, panel M1) while the characteristic profile of epoxy resin contains mostly chlorine $(\mathrm{Cl})$, and oxygen $(\mathrm{O})$ (Fig. 5a, panel M2), and for the microplastic particles, a high peak in oxygen $(\mathrm{O})$ was observed (Fig. 5a, panel M3). The elemental spectra of the epoxy resin and the microplastics show minor traces of calcium $(\mathrm{Ca})$ and magnesium $(\mathrm{Mg})$.

The curve shape of the elemental analysis in the thin section of plastic exposed coral samples, analyses M4 and M5 (Fig. 5b, panel M4 and M5), shows high calcium (Ca) values similar to M1 (Fig. 5a, panel M1) i.e. the coral skeleton in the calibration thin section. M7 (Fig. 5b, panel M7) in the thin section of a microplastic exposed coral is identified as epoxy resin, by its high values in chlorine $(\mathrm{Cl})$, similar to M2 (Fig. 5a, panel M2). Finally, M6 (Fig. 5b, panel M6) in the exposed thin section can be identified as microplastic particle by its similarity to M3 in the calibration thin section (Fig. 5a, panel M3) with its high values in oxygen $(\mathrm{O})$ and the lack of chlorine $(\mathrm{Cl})$. Additionally, elemental weight analysis (Table 1) yielded comparable values.

\section{Fibres encrusted by coral skeleton}

Although fibres were not added to the experiment on purpose, fibres were found to be partially embedded in the coenosteum 


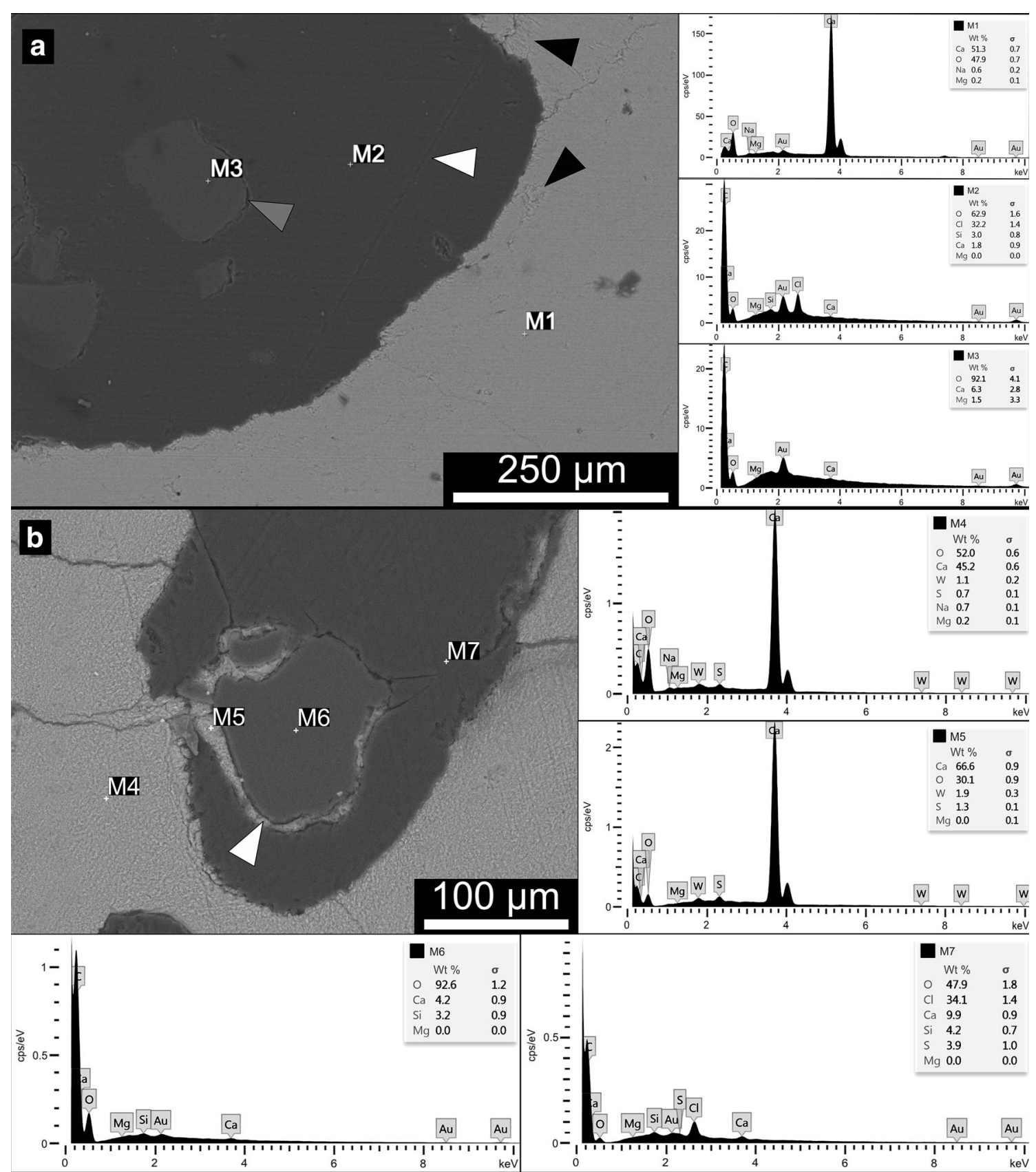

Fig. 5 SEM images including point spectra of EDX measurements. a Artificially produced thin section created before the start of the experimentation. White arrow indicates surface structure of the epoxy resin induced by the cutting process. Black arrow indicates coral internal structure, individual aragonite crystals are visible. Three different measurements were taken (M1, M2, M3). All three measurements exhibit unique elemental spectra. M1 displays an increased amount of calcium $(\mathrm{Ca})$ and oxygen $(\mathrm{O})$. M2 displays an increased amount of oxygen $(\mathrm{O})$ and a peak in chlorine $(\mathrm{Cl})$. M3 displays an increased amount in oxygen $(\mathrm{O})$ and does not have a peak in chlorine

of two coral skeletons of S. hystrix (Fig. 6a, b). The fibres are ca. 3.5 to $4 \mathrm{~mm}$ long, have a black colour and were encrusted in close proximity to the corallites (Fig. 6a, b). SEM analyses revealed carbonate coating of the edges of microfibres.
(Cl). M1 was a measurement of coral skeleton, M2 was a measurement of the epoxy resin and M3 was the measurement of microplastic particles. $\mathbf{b}$ Coral skeleton of $S$. hystrix revealing the possible mechanism of how the microplastic particles were held in place. White arrow indicates the carbonate layer forming around the microplastic particle. Four different measurements (M4, M5, M6, M7) were completed across the sample. M4 compared to M5 resolves a very similar pattern, with only a slight difference in oxygen $(\mathrm{O})$ content was detected. M4 and M5 display high peaks in calcium $(\mathrm{Ca})$. M6 displays a high peak in oxygen $(\mathrm{O})$. M7 displays a high peak in oxygen $(\mathrm{O})$ and a smaller peak in chlorine $(\mathrm{Cl})$

\section{Discussion}

The PET-exposure experiment shows a species-specific impact of microplastic particles on corals, namely, with S. hystrix 
Table 1 Measurements of elemental point spectra in weight percentage (wt\%)

\begin{tabular}{lllllllllll}
\hline Measurement in wt\% & $\mathrm{Ca}$ & $\mathrm{O}$ & $\mathrm{Cl}$ & $\mathrm{Mg}$ & $\mathrm{Na}$ & $\mathrm{Si}$ & $\mathrm{S}$ & $\mathrm{W}$ & Sample \\
\hline M1 & Coral skeleton & 51.27 & 47.88 & - & 0.21 & 0.64 & - & - & - & Calibration thin section of plastics \\
M2 & Epoxy resin & 1.79 & 62.93 & 32.24 & 0 & - & 3.03 & - & - & - \\
M3 & Plastic particle & 6.33 & 92.12 & - & 1.55 & - & - & - & - & Thin section of corals exposed to \\
M4 & Coral skeleton & 45.24 & 51.98 & - & 0.23 & 0.74 & - & 0.75 & 1.07 & plastic (Fig. 5b) \\
M5 & Coral skeleton & 66.62 & 30.15 & - & 0.04 & - & - & 1.31 & 1.89 \\
M6 & Plastic particle & 4.21 & 92.64 & - & 0 & - & 3.15 & - & - & - \\
M7 & Epoxy resin & 9.91 & 47.85 & 34.1 & 0 & - & 4.23 & 3.91 & - & \\
\hline
\end{tabular}

and M. capricornis showing more frequent incorporation of particles. Additionally, S. hystrix displayed higher mucus production in the first hours of exposure compared to P. damicornis, A. valida and M. capricornis (Fig. 3d). This is in agreement with previous observations of species-specific variabilities in coral health responses to microplastics (Reichert et al. 2019). We speculate that the increase in mucus production is critical in the higher trapping rates of microplastics close to the polyps, thus elevating the probability of microplastic incorporation. The increased trapping as observed for $M$. capricornis may be connected to the flat morphology and larger surface area exposed to the settling particles. Settling on the coral surface observed during treatment is thought to increase the availability of particles for the ingestion by individual polyps. In addition, the decrease in flow rate due to the mounting of $M$. capricornis on the grid likely trapped further microplastic particles underneath the coral, as they were not only found on top but also at the bottom side of the skeleton.

The size of most of the microplastic particles observed to be incorporated by corals corresponds to the preferred size of particulate organic matter taken up by scleractinian corals $(\sim 100 \mu \mathrm{m})$ (Mills, 2004). Other studies have shown that corals favour the ingestion of pristine microplastic particles over the original food source of the same size and biofouled plastic particles (Allen et al. 2017; Reichert et al. 2018, 2019; Rotjan et al. 2019; Axworthy and Padilla-Gamiño 2019). This behaviour is thought by Allen et al. (2017) to have been triggered by the chemical composition of the microplastic particles. Uptake subsequently led to gut blockage and false satiation, a depletion of energy levels and ultimately to death in the form of bleaching (Wright et al. 2013; Watts et al. 2015; Hall et al. 2015; Biquand et al. 2017; Allen et al. 2017; Okubo et al. 2018; Hankins et al. 2018; Rotjan et al. 2019; Syakti et al. 2019). A recent study revealed that ingested plastic microspheres were incorporated into the cells of the mesenterial filaments of specimens of the anthozoan genus Exaiptasia after entering the gastrovascular cavity, while migration into the tissue interface is thought to depend on particle size (Okubo et al. 2020).

The observations presented here indicate that corals with larger polyp diameters such as $A$. valida and $P$. damicornis can potentially better control uptake and egestion and thus protect themselves against microplastic pollution than $S$. hystrix and M. capricornis with their smaller polyps. This is in agreement with previous observations that have shown that large polyp species are less affected by microplastic pollution than smaller polyp species (Hankins et al. 2018). Smaller polyps lose their potential to ingest nutritional prey while they are busy coping with ingested microplastic particles (Rotjan et al. 2019). Moreover, particles with a bigger diameter may become lodged inside a coral's gastrovascular space more easily.

After ingestion, if microplastic particles pass into the coral gut cavity, they are likely overgrown by tissue and then later encrusted in the tissue by carbonate skeleton material. The encrustation of microplastic particles in the skeleton of S. hystrix supports the overgrowth hypothesis suggested by
Fig. 6 Microplastic fibre incorporation. a $S$. hystrix skeleton displaying an embedded microfibre (length: $\sim 3861.44 \mu \mathrm{m}$ ) (F). b Partial entanglement of microfibre (length: $\sim 3462.13 \mu \mathrm{m}$ ) (F). Fibres positioned across multiple corallites

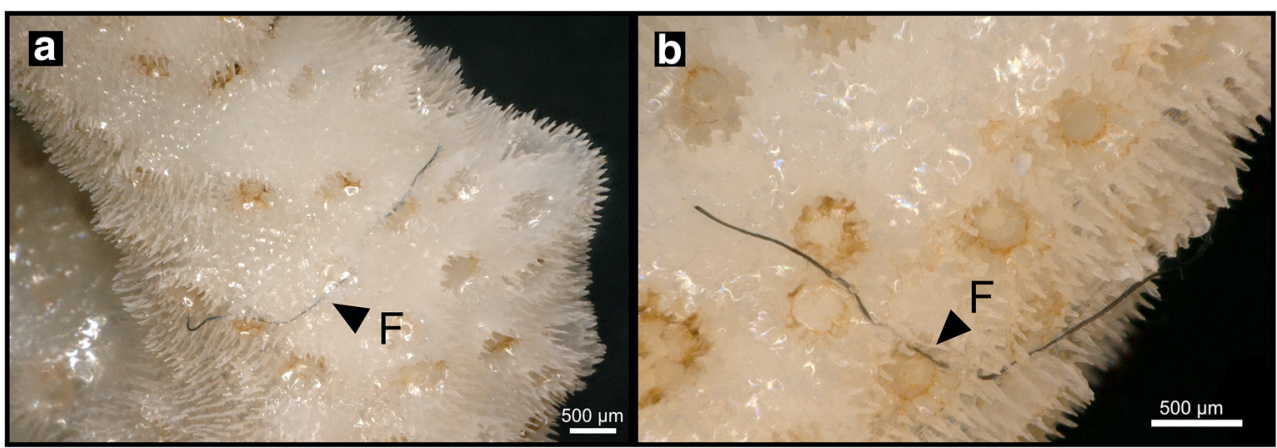




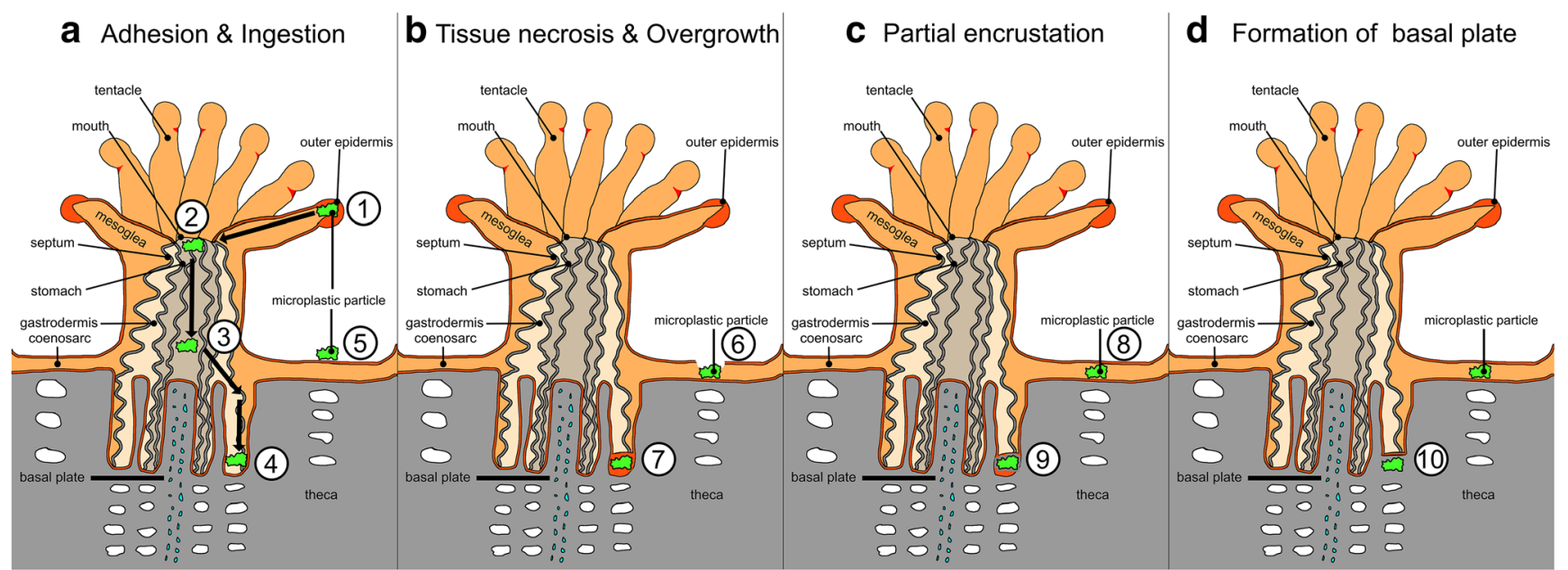

Fig. 7 Possible microplastic incorporation scenario. a (1) Microplastic particle becomes adhesive to the outer epidermis area of the coral tentacle. (2) Food response is triggered and the particle is transported to the mouth of the polyp. (3) Ingestion begins and the particle is transported into the gastrovascular cavity. (4) The microplastic particle becomes stuck inside the gastral area. (5) Adhesion to the coenosarc as a possible mechanism of attachment. b (6) Tissue necrosis occurs and particles migrate into the

Reichert et al. (2018), where plastic particles were overgrown by coral tissue as a result of necrosis. In our experiment, the two encrusted particles are located at the bottom of a corallite in the area of the lower gastrointestinal tract of the polyp (Figs. $4 \mathrm{~b}$ and $5 \mathrm{~b}$ ). The particles are surrounded by aragonite, in one case connected to the skeleton. The mechanism of encrustation is interpreted as the formation of a new basal plate around the particle. A similar incorporation pattern was shown for sediments of non-carbonate origin trapped in between dissepiments and basal plates of Solenastrea hyades, Pavona gigantea and Montastrea annularis (Barnard et al. 1974).

Another mode of overgrowth and encrustation is seen around fibres that were found incorporated in the coral skeleton (Fig. 6a and b). These fibres are likely sourced by prevailing airborne contamination during the experiment in the open tank system, or might be introduced in the system by the sea salt used. Sea salt produced for human consumption was recently shown to contain microplastics (Peixoto et al. 2019); thus, it is likely that sea salt for aquarium use produced under less stringent controls than for human consumption might contain microplastic particles and fibres. These fibres were found encrusted in the coenchym areas in between corallites. A plausible mechanism for fibre encrustation is that after settling on the outer edges of the polyps, they got entangled between polyps beyond their reach of active removal. Similar entanglement and overgrowth of monofilament fishing lines have previously been observed (Smith and Hattori 2008).

The overgrowth by coral tissue and skeleton may be a result of a temporal tissue necrosis resulting from microplastic adhesion (Reichert et al. 2018; Martin et al. 2019; Corona et al. 2020). Following necrosis, the damaged tissue is recolonised by intact tissue, partially encrusting the foreign tissue. (7) Tissue healing process starts and the particle is overgrown by tissue material. c (8) Tissue healing process is completed. The particle is fully surrounded by coral tissue. (9) Partial overgrowth by aragonite is induced. Aragonite crystals form a layer surrounding the foreign body, later connected to the theca. $\mathbf{d}$ (10) The formation of a new basal plate surrounding the microplastic particle by encrustation is complete

fibre or particle (Fig. 6a and b) and incorporating it into the skeletal material (Fig. 4b). The microplastic particles or fibres become adhesive to the coral surface structure, either by attachment to the tentacle or the coenosarc (Fig. 7a). When caught by a tentacle, the immediate food response of the coral is triggered and ingestion begins (Fig. 7a), as also described earlier (Allen et al. 2017). Upon reaching the gastral area, plastic particles become stuck inside the gastrovascular cavity inducing tissue necrosis. Tissue necrosis usually occurs directly in connection with surface exposure to microplastic (Reichert et al. 2018). This process is followed by clonal tissue overgrowth as healing mechanism of the tissue damage (Fig. $7 b)$. Following the complete tissue overgrowth, partial encrustation by aragonite material takes place (Fig. 7c) as aragonite crystals form around the foreign body and induce the formation of a new basal plate (Fig. 7c). When the formation of a new basal plate is completed, the microplastic material is fully embedded in the coral skeleton (Fig. 7d).

Although PET concentrations of $0.5 \mathrm{~g} \mathrm{~L}^{-1}$ in the experiment were above concentrations occurring in the environment (Reisser et al. 2013; Syakti et al. 2017; Ding et al. 2019; Jensen et al. 2019), the observed effects may increase and accumulate over the lifetime of a coral colony. Concentrations in polluted environments on a reef flat

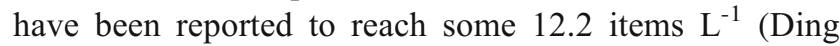
et al. 2019). It has been shown that rejection, ingestion, and egestion are energy consuming (Reichert et al. 2019) as are the increased mucus production and active particle removal (Wild et al. 2004). In the end, however, the low portion of microplastic particles incorporated compared to the high concentration of exposure indicates that corals are very efficient in removing and rejecting microplastics, 
P. damicornis and A. valida even more successful than $S$. hystrix and M. capricornis.

In a future that is expected to see increased plastic littering, coral reef environments may become a major sink for microplastics by adhesion, ingestion, and skeletal incorporation (Reichert et al. 2018; Martin et al. 2019; Corona et al. 2020). It has been shown that short-term exposure to microplastics results in minor to almost no effect on the coral calcification rates (Hankins et al. 2018). However, no information is as yet available on the long-term effects of exposure to microplastics. We speculate that because species with larger polyp diameters may be less impacted than species with smaller polyp diameters, a shift in species composition might result from long-term exposure to high loads of microplastic pollution. Our results additionally imply that microplastics incorporated into the coral skeletal materials might enter the food chain of grazers such as corallivorous fish, and ultimately appear in the human diet (Andrady 2011). The particles may be released again in the water column after bioerosive processes such as Parrotfish bites (Hutchings 1986).

Supplementary Information The online version contains supplementary material available at https://doi.org/10.1007/s11356-021-13240-x.

Acknowledgements We are grateful to S. Hardenberg, J. García, N. Steinel, L. Röpke, N. Paul and C. Brandt of the ZMT Marine Experimental Ecology Facility (MAREE) for providing advice, support and technical assistance; S. Flotow for thin section preparation; A. Wizemann for SEM support and help with general design of the tank setup; A. Feuring for assistance in aquaria maintenance and sample preparation. We thank S. Doo, G. Murphy and M. Kunkel for suggestions and valuable comments on an earlier version of the manuscript. We thank the anonymous reviewers for their constructive feedback and helpful comments.

Author contribution F. Hierl, H. C. Wu and H. Westphal initiated the original project. F. Hierl, H. Westphal and H. C. Wu conceptualized the research. F. Hierl conducted the tank experiments, sample processing and analyses of the samples and served as primary author on this manuscript. All authors contributed to interpretation, editing, discussed the results and wrote the manuscript.

Funding Open Access funding enabled and organized by Projekt DEAL. This research is part of the doctoral thesis of Florian Hierl. It was supported by the Leibniz Centre for Tropical Marine Research (ZMT) under Core Budget Project: PlastiCoralsGeo to H. Westphal.

Data availability The datasets used and analysed during the current study are available from the corresponding author on reasonable request.

\section{Declarations}

Ethics approval and consent to participate All animal procedures were in accordance with the regulations of the German Animal Welfare Act and were approved by the local authorities.

Consent for publication Not applicable.
Competing interests The authors declare no competing interests.

Open Access This article is licensed under a Creative Commons Attribution 4.0 International License, which permits use, sharing, adaptation, distribution and reproduction in any medium or format, as long as you give appropriate credit to the original author(s) and the source, provide a link to the Creative Commons licence, and indicate if changes were made. The images or other third party material in this article are included in the article's Creative Commons licence, unless indicated otherwise in a credit line to the material. If material is not included in the article's Creative Commons licence and your intended use is not permitted by statutory regulation or exceeds the permitted use, you will need to obtain permission directly from the copyright holder. To view a copy of this licence, visit http://creativecommons.org/licenses/by/4.0/.

\section{References}

Allen AS, Seymour AC, Rittschof D (2017) Chemoreception drives plastic consumption in a hard coral. Mar Pollut Bull 124:198-205. https://doi.org/10.1016/j.marpolbul.2017.07.030

Andrady AL (2011) Microplastics in the marine environment. Mar Pollut Bull 62:1596-1605. https://doi.org/10.1016/j.marpolbul.2011.05. 030

Ashton K, Holmes L, Turner A (2010) Association of metals with plastic production pellets in the marine environment. Mar Pollut Bull 60: 2050-2055. https://doi.org/10.1016/J.MARPOLBUL.2010.07.014

Axworthy JB, Padilla-Gamiño JL (2019) Microplastics ingestion and heterotrophy in thermally stressed corals. Sci Rep 9:1-8. https:// doi.org/10.1038/s41598-019-54698-7

Bakir A, Rowland SJ, Thompson RC (2012) Competitive sorption of persistent organic pollutants onto microplastics in the marine environment. Mar Pollut Bull 64:2782-2789. https://doi.org/10.1016/J. MARPOLBUL.2012.09.010

Barnard LA, Macintyre IG, Pierce JW (1974) Possible environmental index in tropical reef corals. Nature 252:219-220. https://doi.org/ $10.1038 / 252219 \mathrm{a} 0$

Barnes DKA, Galgani F, Thompson RC, Barlaz M (2009) Accumulation and fragmentation of plastic debris in global environments. Philos Trans R Soc Lond Ser B Biol Sci 364:1985-1998. https://doi.org/ 10.1098/rstb.2008.0205

Berloff PS, McWilliams JC, Bracco A (2002) Material transport oceanic gyres. Part I: Phenomenology. J Phys Oceanogr 32:764-796. https:// doi.org/10.1175/1520-0485(2002)032<0764:MTIOGP >2.0.CO;2

Biquand E, Okubo N, Aihara Y, Rolland V, Hayward DC, Hatta M, Minagawa J, Maruyama T, Takahashi S (2017) Acceptable symbiont cell size differs among cnidarian species and may limit symbiont diversity. ISME J 11:1702-1712. https://doi.org/10.1038/ismej. 2017.17

Browne MA, Galloway TS, Thompson RC (2010) Spatial patterns of plastic debris along estuarine shorelines. Environ Sci Technol 44: 3404-3409. https://doi.org/10.1021/es903784e

Carpenter EJ, Anderson SJ, Harvey GR, Miklas HP, Peck BB (1972) Polystyrene spherules in coastal waters. Science 178:749-750. https://doi.org/10.1126/science.178.4062.749

Carpenter EJ, Smith KLJ (1972) Plastics on the Sargasso sea surface. Science 175:1240-1241. https://doi.org/10.1126/science.175.4027. 1240

Cole M, Lindeque P, Halsband C, Galloway TS (2011) Microplastics as contaminants in the marine environment: a review. Mar Pollut Bull 62:2588-2597. https://doi.org/10.1016/J.MARPOLBUL.2011.09. 025

Connors EJ (2017) Distribution and biological implications of plastic pollution on the fringing reef of Mo'orea, French Polynesia. PeerJ 5:e3733. https://doi.org/10.7717/peerj.3733 
Corona E, Martin C, Marasco R, Duarte CM (2020) Passive and active removal of marine microplastics by a mushroom coral (Danafungia scruposa). Front Mar Sci 7:1-9. https://doi.org/10.3389/fmars.2020. 00128

Derraik JGB (2002) The pollution of the marine environment by plastic debris: a review. Mar Pollut Bull 44:842-852. https://doi.org/10. 1016/S0025-326X(02)00220-5

Ding J, Jiang F, Li J, Wang Z, Sun C, Wang Z, Fu L, Ding NX, He C (2019) Microplastics in the coral reef systems from Xisha islands of South China Sea. Environ Sci Technol 53:8036-8046. https://doi. org/10.1021/acs.est.9b01452

Duckworth A, Giofre N, Jones R (2017) Coral morphology and sedimentation. Mar Pollut Bull 125:289-300. https://doi.org/10.1016/j. marpolbul.2017.08.036

Eriksen M, Lebreton LCM, Carson HS, Thiel M, Moore CJ, Borerro JC, Galgani F, Ryan PG, Reisser J (2014) Plastic pollution in the world's oceans: more than 5 trillion plastic pieces weighing over 250,000 tons afloat at sea. PLoS One 9:e111913. https://doi.org/ 10.1371/journal.pone. 0111913

Eriksen M, Mason S, Wilson S, Box C, Zellers A, Edwards W, Farley H, Amato S (2013) Microplastic pollution in the surface waters of the Laurentian Great Lakes. Mar Pollut Bull 77:177-182. https://doi. org/10.1016/j.marpolbul.2013.10.007

Fendall LS, Sewell MA (2009) Contributing to marine pollution by washing your face: microplastics in facial cleansers. Mar Pollut Bull 58: 1225-1228. https://doi.org/10.1016/J.MARPOLBUL.2009.04.025

Fischer V, Elsner NO, Brenke N, Schwabe E, Brandt A (2015) Plastic pollution of the kuril-kamchatka trench area (NW pacific). Deep Sea Res Part II Top Stud Oceanogr 111:399-405. https://doi.org/10. 1016/j.dsr2.2014.08.012

Fisner M, Taniguchi S, Moreira F, Bícego MC, Turra A (2013) Polycyclic aromatic hydrocarbons (PAHs) in plastic pellets: variability in the concentration and composition at different sediment depths in a sandy beach. Mar Pollut Bull 70:219-226. https://doi. org/10.1016/J.MARPOLBUL.2013.03.008

Fowler CW (1987) Marine debris and northern fur seals: a case study. Mar Pollut Bull 18:326-335. https://doi.org/10.1016/S0025326X(87)80020-6

GESAMP (2015) Sources, fate and effects of microplastics in the marine environment: a global assessment (Kershaw, P. J., ed.). (IMO/FAO/ UNESCO-IOC/UNIDO/WMO/IAEA/UN/UNEP/UNDP Joint Group of Experts on the Scientific Aspects of Marine Environmental Protection). Rep Stud GESAMP No. 90:96 p

Gewert B, Plassmann MM, MacLeod M (2015) Pathways for degradation of plastic polymers floating in the marine environment. Environ Sci Process Impacts 17:1513-1521. https://doi.org/10.1039/ C5EM00207A

Gregory MR (1991) The hazards of persistent marine pollution: drift plastics and conservation islands. J R Soc N Z 21:83-100. https:// doi.org/10.1080/03036758.1991.10431398

Hahladakis JN, Velis CA, Weber R, Iacovidou E, Purnell P (2018) An overview of chemical additives present in plastics: migration, release, fate and environmental impact during their use, disposal and recycling. J Hazard Mater 344:179-199

Hall NM, Berry KLE, Rintoul L, Hoogenboom MO (2015) Microplastic ingestion by scleractinian corals. Mar Biol 162:725-732. https://doi. org/10.1007/s00227-015-2619-7

Hankins C, Duffy A, Drisco K (2018) Scleractinian coral microplastic ingestion: potential calcification effects, size limits, and retention. Mar Pollut Bull 135:587-593. https://doi.org/10.1016/j.marpolbul. 2018.07.067

Hutchings PA (1986) Biological destruction of coral reefs - a review. Coral Reefs 4:239-252. https://doi.org/10.1007/BF00298083

Jambeck JR, Geyer R, Wilcox C, Siegler TR, Perryman M, Andrady A, Narayan R, Law KL (2015) Marine pollution. Plastic waste inputs from land into the ocean. Science 347:768-771. https://doi.org/10. 1126/science. 1260352

Jensen LH, Motti CA, Garm AL, Tonin H, Kroon FJ (2019) Sources, distribution and fate of microfibres on the Great Barrier Reef, Australia. Sci Rep 9:9021. https://doi.org/10.1038/s41598-01945340-7

Kane IA, Clare MA, Miramontes E, Wogelius R, Rothwell JJ, Garreau P, Pohl F (2020) Seafloor microplastic hotspots controlled by deep-sea circulation. Science 368:1140-1145. https://doi.org/10.1126/ science.aba5899

Kirstein IV, Kirmizi S, Wichels A, Garin-Fernandez A, Erler R, Löder M, Gerdts G (2016) Dangerous hitchhikers? Evidence for potentially pathogenic Vibrio spp. on microplastic particles. Mar Environ Res 120:1-8. https://doi.org/10.1016/j.marenvres.2016.07.004

Lamb JB, Willis BL, Fiorenza EA, Couch CS, Howard R, Rader DN, True JD, Kelly LA, Ahmad A, Jompa J, Harvell CD (2018) Plastic waste associated with disease on coral reefs. Science 359:460-462. https://doi.org/10.1126/science.aar3320

Madin JS, Anderson KD, Andreasen MH, Bridge TCL, Cairns SD, Connolly SR, Darling ES, Diaz M, Falster DS, Franklin EC, Gates RD, Harmer AMT, Hoogenboom MO, Huang D, Keith SA, Kosnik MA, Kuo CY, Lough JM, Lovelock CE, Luiz O, Martinelli J, Mizerek T, Pandolfi JM, Pochon X, Pratchett MS, Putnam HM, Roberts TE, Stat M, Wallace CC, Widman E, Baird AH (2016) The Coral Trait Database, a curated database of trait information for coral species from the global oceans. Sci Data 3:16. https://doi. org/10.1038/sdata.2016.17

Martin C, Corona E, Mahadik GA, Duarte CM (2019) Adhesion to coral surface as a potential sink for marine microplastics. Environ Pollut 255:113281. https://doi.org/10.1016/j.envpol.2019.113281

Maximenko N, Hafner J, Niiler P (2012) Pathways of marine debris derived from trajectories of Lagrangian drifters. Mar Pollut Bull 65:51-62. https://doi.org/10.1016/j.marpolbul.2011.04.016

Moore CJ (2008) Synthetic polymers in the marine environment: a rapidly increasing, long-term threat. Environ Res 108:131-139. https:// doi.org/10.1016/j.envres.2008.07.025

Okubo N, Takahashi S, Nakano Y (2018) Microplastics disturb the anthozoan-algae symbiotic relationship. Mar Pollut Bull 135:8389. https://doi.org/10.1016/j.marpolbul.2018.07.016

Okubo N, Tamura-Nakano M, Watanabe T (2020) Experimental observation of microplastics invading the endoderm of anthozoan polyps. Mar Environ Res 162:105125. https://doi.org/10.1016/j.marenvres. 2020.105125

Peixoto D, Pinheiro C, Amorim J, Oliva-Teles L, Guilhermino L, Vieira MN (2019) Microplastic pollution in commercial salt for human consumption: a review. Estuar Coast Shelf Sci 219:161-168

Pruter AT (1987) Sources, quantities and distribution of persistent plastics in the marine environment. Mar Pollut Bull 18:305-310. https://doi. org/10.1016/S0025-326X(87)80016-4

Reichert J, Arnold AL, Hoogenboom MO, Schubert P, Wilke T (2019) Impacts of microplastics on growth and health of hermatypic corals are species-specific. Environ Pollut 254:113074. https://doi.org/10. 1016/j.envpol.2019.113074

Reichert J, Schellenberg J, Schubert P, Wilke T (2018) Responses of reef building corals to microplastic exposure. Environ Pollut 237:955960. https://doi.org/10.1016/j.envpol.2017.11.006

Reisser J, Shaw J, Wilcox C, Hardesty BD, Proietti M, Thums M, Pattiaratchi C (2013) Marine plastic pollution in waters around Australia: characteristics, concentrations, and pathways. PLoS One 8:e80466. https://doi.org/10.1371/journal.pone.0080466

Reisser J, Slat B, Noble K, du Plessis K, Epp M, Proietti M, de Sonneville J, Becker T, Pattiaratchi C (2015) The vertical distribution of buoyant plastics at sea: an observational study in the North Atlantic Gyre. Biogeosciences 12:1249-1256. https://doi.org/10.5194/bg-121249-2015 
Rios LM, Moore C, Jones PR (2007) Persistent organic pollutants carried by synthetic polymers in the ocean environment. Mar Pollut Bull 54: 1230-1237. https://doi.org/10.1016/j.marpolbul.2007.03.022

Rotjan RD, Sharp KH, Gauthier AE, Yelton R, Lopez EMB, Carilli J, Kagan JC, Urban-Rich J (2019) Patterns, dynamics and consequences of microplastic ingestion by the temperate coral, Astrangia poculata. Proc R Soc B Biol Sci 286:20190726. https:// doi.org/10.1098/rspb.2019.0726

Warne SSJ (1962) A quick field or laboratory staining scheme for the differentiation of the major carbonate minerals. SEPM J Sediment Res 32:29-38. https://doi.org/10.1306/74D70C40-2B21-11D7$8648000102 \mathrm{C} 1865 \mathrm{D}$

Schneider CA, Rasband WS, Eliceiri KW (2012) NIH image to ImageJ: 25 years of image analysis. Nat Methods 9:671-675

Smith SDA, Hattori H (2008) Corals versus monofilament: corals fight back in Savusavu Bay, Fiji. Coral Reefs 27:321. https://doi.org/10. 1007/s00338-007-0340-9

Stamper MA, Whitaker BR, Schofield TD (2006) Case study: morbidity in a pygmy sperm whale kogia breviceps due to ocean-bourne plastic. Mar Mammal Sci 22:719-722. https://doi.org/10.1111/j.17487692.2006.00062.x

Stefatos A, Charalampakis M, Papatheodorou G, Ferentinos G (1999) Marine debris on the seafloor of the mediterranean sea: examples from two enclosed gulfs in Western Greece. Mar Pollut Bull 38: 389-393. https://doi.org/10.1016/S0025-326X(98)00141-6

Syakti AD, Bouhroum R, Hidayati NV, Koenawan CJ, Boulkamh A, Sulistyo I, Lebarillier S, Akhlus S, Doumenq P, Wong-WahChung P (2017) Beach macro-litter monitoring and floating microplastic in a coastal area of Indonesia. Mar Pollut Bull 122: 217-225. https://doi.org/10.1016/J.MARPOLBUL.2017.06.046

Syakti AD, Jaya JV, Rahman A, Hidayati NV, Raza'i TS, Idris F, Trenggono M, Doumenq P, Chou LM (2019) Bleaching and necrosis of staghorn coral (Acropora formosa) in laboratory assays: immediate impact of LDPE microplastics. Chemosphere 228:528-535. https://doi.org/10.1016/j.chemosphere.2019.04.156

Tan F, Yang H, Xu X, Fang Z, Xu H, Shi Q, Zhang X, Wang G, Lin L, Zhou S, Huang L, Li H (2020) Microplastic pollution around remote uninhabited coral reefs of Nansha Islands, South China Sea. Sci
Total Environ 725:138383. https://doi.org/10.1016/j.scitotenv. 2020.138383

Teuten EL, Rowland SJ, Galloway TS, Thompson RC (2007) Potential for plastics to transport hydrophobic contaminants. Environ Sci Technol 41:7759-7764. https://doi.org/10.1021/es071737s

Teuten EL, Saquing JM, Knappe DRU, Barlaz MA, Jonsson S, Björn A, Rowland SJ, Thompson RC, Galloway TS, Yamashita R, Ochi D, Watanuki Y, Moore C, Viet PH, Tana TS, Prudente M, Boonyatumanond R, Zakaria MP, Akkhavong K, Ogata Y, Hirai H, Iwasa S, Mizukawa K, Hagino Y, Imamura A, Saha M, Takada $H$ (2009) Transport and release of chemicals from plastics to the environment and to wildlife. Philos Trans R Soc B Biol Sci 364: 2027-2045. https://doi.org/10.1098/rstb.2008.0284

Van Cauwenberghe L, Devriese L, Galgani F et al (2015) Microplastics in sediments: a review of techniques, occurrence and effects. Mar Environ Res 111:5-17. https://doi.org/10.1016/j.marenvres.2015. 06.007

Wang J, Tan Z, Peng J, Qiu Q, Li M (2016) The behaviors of microplastics in the marine environment. Mar Environ Res 113:717

Watts AJR, Urbina MA, Corr S, Lewis C, Galloway TS (2015) Ingestion of plastic microfibers by the crab carcinus maenas and its effect on food consumption and energy balance. Environ Sci Technol 49: 14597-14604. https://doi.org/10.1021/acs.est.5b04026

Weinstein JE, Crocker BK, Gray AD (2016) From macroplastic to microplastic: degradation of high-density polyethylene, polypropylene, and polystyrene in a salt marsh habitat. Environ Toxicol Chem 35:1632-1640. https://doi.org/10.1002/etc.3432

Wild C, Huettel M, Klueter A, Kremb SG, Rasheed MYM, Jørgensen BB (2004) Coral mucus functions as an energy carrier and particle trap in the reef ecosystem. Nature 428:66-70. https://doi.org/10.1038/ nature 02344

Wright SL, Thompson RC, Galloway TS (2013) The physical impacts of microplastics on marine organisms: a review. Environ Pollut 178: 483-492. https://doi.org/10.1016/J.ENVPOL.2013.02.031

Publisher's note Springer Nature remains neutral with regard to jurisdictional claims in published maps and institutional affiliations. 